\section{Insuring Nuclear Power}

VERY soon, the Paris convention on third party liability in nuclear energy will come into force. The convention, which provides the principles on which international agreements on nuclear liability are based, was signed in Paris on July 20, 1960, but does not come into force until it and ar. additional protocol are ratified by five governments. The convention has now been ratified by Turkey, Spain, the United Kingdom, France and Belgium; the additional protocol, which is designed to avoid conflict with another international conventionthe convention on civil liability for nuclear damage, defined by a conference in 1963 convened by the International Atomic Energy Agency-has been signed by the same group, with the exception of Turkey. Turkcy is now on the verge of ratifying the protocol, whereupon the whole convention will come into force.

The subject is complicated. Briefly, the convention provides five principles on which legislation should be based. The operator of the nuclear station is absolutely and exclusively liable-without proof that it is his fault - for any accident, but only if claims are made within ten years of the incident. The convention limits the amount of liability, in principle, to $\$ 15$ million, and obliges the operator to cover his liability by insurance or otherwise. All claims arising from the same incident should be dealt with in the same court, in the place where the incident took place, and all countries who are party to the convention are obliged to accept the court's rulings. In 1963, the provisions of the convention were extended to provide additional compensation, up to a value of $\$ 120$ million, through State intervention.

The convention falls under the jurisdiction of the European Nuclear Energy Agency, which has now published a review of the legislation which obtains in fourteen OECD countries and of how this meets the needs of the Paris convention. Most of the countries have legislation which incorporates the principles of the convention, and some go beyond it. There are, however, some differences-in Japan, for example, accidents during transport are the liability of the consignee. In Germany, there is no provision to limit liability in the event of force majeure. Most countries incorporate clauses which free the operator from liability in such cases, or when the claimant was injured as a result of his own negligence or a wilful act. In the United Kingdom, when the victim has been guilty of committing an act with the intention of causing harm or with reckless disregard for the consequences, the amount of compensation may be reduced. In the United States, the cost of an accident can be even greater-the law provides for liability of up to $\$ 560$ million.

\section{Books to Borrow}

"NeTrHer a borrower nor a lender be" may have been good advice for Hamlet, but luckily for the British general public there are people who do not take it too seriously. The National Central Library borrows and lends more each year from its stock of volumes, which has doubled over the past five years to the present total of 364,000 . 1,037 current periodicals are taken, 68 of them being in Slavonic languages. The library, which is largely financed by the Department of Educa- tion and Science- $£ 141,000$ last year-has just produced its annual report for 1966-67.

The British library system works on a two-tier basis, with the central library available to answer requests from both parts. Most libraries belong to regional systems, which are as far as possible selfsufficient. Unsatisfied queries are passed on to the central library. Other libraries which, for one reason or another, are not included in any regional system form the second tier and have direct contact with the central library. As overall centre of the national interloan system, the central library handled 136,660 requests during $1966-67$, with 77.5 per cent success. compared with $128,567,75 \cdot 2$ per cent, in the previous year. Through the co-operating libraries the central library has access to some 20 million volumes. 7,969 overseas requests were received, of which 83.1 per cent were satisfied, as were 72 per cent of the 9,954 requests made by the central library to those abroad. The total number of applications received by the library rose by 6.3 per cent and were handled despite staff shortages. A successful year was recorded by the library, but it ended with the resignation of its chairman because of ill health. Lord Elgin, associated with the library since its reconstruction in 1930 and chairman of the trustees since 1955, had presided over many important developments in the library's affairs.

Another library publication appeared this week, a list of the current serials received by the National Lending Library for Science and Technology at Boston Spa, Yorkshire. (HMSO, £2.) The alphabetical list has been produced as a by-product of the recording system at the library, and, it is stated, may not include a certain number of titles which are in fact available. Only those titles which were current and at the library in March 1967 are included, but not those which were on order. The list is not intended to deter those who would like to borrow periodicals that are not mentioned, as the library relies on such requests for titles of serials that should be obtained. A large number of cyrillic titles are included in the total of 26,000 , and for the first time the social sciences are covered.

\section{Fission of Physics Journals}

The Institute of Physics and the Physical Society (which is the name for a single learned society) is embarking on an important change in its publications policy. The Proceedings of the Physical Society is to be split into three sections to be known as Journal of Physics $A, B$ and $C$ dealing respectively with general physics, atomic and molecular physics and solid state physics. The intention is that contributions to the three sections will appear six times a year in alternate months. The price of subscriptions to the new journals is to be $£ 40$ (for 18 issues a year) which is more than a proportionate increase on the cost of $£ 24$ for one subscription to 12 issues of the Proceedings. It will, however, be possible for non-members of the society to take out separate subscriptions to the three parts at a cost of $£ 15$ each.

By making this change, the British society is clearly following in the steps of the American Physical Society, which publishes The Physical Review and which split this into separate sections at the beginning of 1967 . Only time will tell whether the obvious advantages of 